\title{
Nomenclature et classification des entérovirus : quelle histoire !
}

\author{
Maël Bessaud ${ }^{1,2}$ \\ Bruno Blondel ${ }^{1}$ \\ Marie-Line Joffret ${ }^{1,2}$ \\ Alice Mac Kain ${ }^{1,3}$ \\ Francis Delpeyroux ${ }^{1,2}$ \\ ${ }^{1}$ Institut Pasteur, \\ Unité de biologie des virus entériques, \\ 25-28 rue du Dr Roux, \\ 75015 Paris, France \\ ${ }^{2}$ Centre collaborateur de l'OMS \\ pour les entérovirus \\ et les vaccins viraux, \\ 25-28 rue du Dr Roux, \\ 75015 Paris, France \\ <mael.bessaud@pasteur.fr> \\ ${ }^{3}$ Université Paris Diderot, \\ Sorbonne Paris Cité, \\ 5 rue Thomas Mann, \\ 75013 Paris, France
}

\begin{abstract}
Résumé. Depuis l'identification des premiers entérovirus, la classification et la nomenclature de ces virus ont été remaniées à de nombreuses reprises. Le fondement même de la classification a été modifié au cours des années 2000 lorsque les critères génétiques ont supplanté les critères sérologiques pour l'identification et la classification des entérovirus. Fruit de ces remaniements, la classification et la nomenclature actuelles sont souvent assez déroutantes pour l'étudiant, le chercheur ou le praticien qui s'intéresse pour la première fois à ces virus ; coxsackievirus A et B côtoient echovirus et poliovirus au sein de différentes espèces tandis que, de façon peu intuitive au regard de l'étymologie, les rhinovirus appartiennent désormais au genre Enterovirus. Cette revue a pour but de présenter un aperçu historique des méthodes et des concepts qui ont été utilisés pour élaborer les classifications successives de ces virus et des découvertes qui ont conduit à les réformer. Souvent subtiles, parfois profondes, les modifications apportées au cours du temps retracent l'histoire de nos connaissances concernant les entérovirus et celle de notre compréhension de la diversité qu'ils présentent ; en creux, elles révèlent surtout notre ignorance.
\end{abstract}

Mots clés : entérovirus, coxsackievirus, echovirus, poliovirus, taxonomie

\begin{abstract}
Since the identification of the first enteroviruses, the classification and the nomenclature of these viruses were modified several times. Even the base of the classification was changed during the 2000s when genetic criteria superseded the historical serological criteria used to identify enteroviruses. Product of these modifications, the current classification and nomenclature are confusing for students, researchers and practitioners who discover them for the first time; coxsackieviruses A and B, echoviruses and polioviruses are gathered into different species while surprisingly, in view of the etymology, the rhinoviruses now belong the genus Enterovirus. This review aims to summarize the history of the methods and concepts that were used to elaborate the successive classifications and to feature the discoveries that led to their modifications. Mostly slight, sometimes drastic, these modifications underline the history of our knowledge about the enteroviruses and their diversity; indirectly, they highlight our profound ignorance.
\end{abstract}

Key words: enterovirus, coxsackievirus, echovirus, poliovirus, taxonomy
Les entérovirus appartiennent à la famille des Picornaviridae [1]. Cette famille est constituée de petits virus à ARN, d'où leur nom adopté en 1963 («pico» : très petit et «rna»: ribonucleic acid) [2]. Ils possèdent une capside icosaédrique non enveloppée et leur génome est constitué d'une molécule unique d'ARN monocaténaire. Ce génome sert d'ARN messager pour initier le cycle viral qui se déroule

Tirés à part : M. Bessaud dans le cytoplasme des cellules infectées. Le génome comporte un long cadre de lecture flanqué de deux régions non traduites qui participent à la traduction et à la réplication du génome. Le cadre de lecture code une polyprotéine unique qui subit une série de clivages protéolytiques donnant naissance aux protéines virales fonctionnelles (figure 1).

La classification des entérovirus est en constante évolution depuis l'identification des premiers membres de cette population virale relativement hétérogène. La classification 


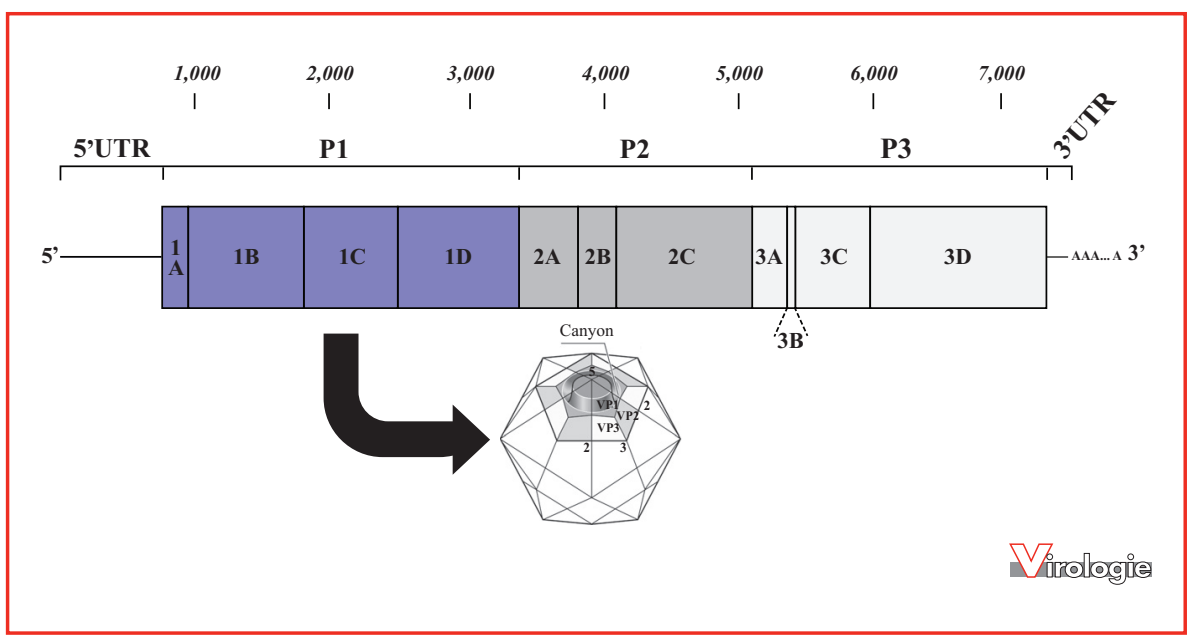

Figure 1. Organisation du génome et de la capside des entérovirus. Le génome est composé d'une molécule unique d'ARN monocaténaire de polarité positive. Deux régions non codantes (5'UTR et 3'UTR) flanquent une phase ouverte de lecture unique codant une polyprotéine qui subit une série de clivages protéolytiques pour générer l'ensemble des protéines virales. La région $\mathrm{P} 1$ code les protéines de capside (VP1 à VP4) ; celles-ci s'agencent pour former la capside des virions qui présente une structure icosaédrique (la protéine VP4 est interne). Les régions P2 et P3 codent les protéines non structurales impliquées notamment dans les clivages protéolytiques et la réplication du génome viral.

actuelle de ces virus est principalement basée sur l'homologie de la séquence des molécules d'ARN simple brin qui constituent leur génome. Les entérovirus sont ainsi divisés en 15 espèces : les entérovirus $\mathrm{A}$ à $\mathrm{L}$ et les rhinovirus $\mathrm{A}$ à $\mathrm{C}$ (figure 2). Cette classification est souvent assez déroutante pour l'étudiant ou le chercheur qui s'intéresse pour la première fois à ces virus. En effet, plusieurs groupes d'entérovirus partageant des propriétés communes (tropisme, pathogénicité pour l'homme ou la souris, sensibilité aux $\mathrm{pH}$ acides, etc.) sont à présent classés dans des espèces différentes et, réciproquement, des virus aux propriétés différentes sont rassemblés au sein d'une même espèce. En fait, dans cette classification, l'identité de chacun de ces virus semble réduite à une succession de nucléotides et nous perdons ainsi le lien avec les propriétés virales intrinsèques qui ont permis de les différencier.

Dans cette revue, nous ferons le point sur l'histoire de la découverte des différents entérovirus ainsi que sur leur pathogénicité respective, deux éléments souvent à l'origine de la première nomenclature de ces virus. Nous verrons également comment les analyses phylogénétiques ont conduit à des remaniements en profondeur de la classification d'origine de ces virus.

\section{Les entérovirus historiques: poliovirus, coxsackievirus et echovirus}

À l'origine, le groupe des entérovirus regroupait des virus ayant des propriétés physicochimiques similaires (den- sité en chlorure de césium, résistance aux $\mathrm{pH}$ acides) et se multipliant principalement dans le tractus digestif de l'hôte infecté. L'infection par ces virus se fait généralement par la voie féco-orale. Elle passe la plupart du temps inaperçue et reste bénigne mais l'atteinte, proportionnellement rare, d'autres organes (le système nerveux central, le cœur, etc.) peut provoquer des pathologies graves. En dehors de leur habitat, une des principales caractéristiques qui distinguaient les entérovirus des autres picornavirus était leur stabilité aux pH acides. Grâce à cette stabilité, ils peuvent transiter à travers l'estomac pour atteindre le tractus intestinal et poursuivre leur multiplication commencée dans l'oropharynx.

À partir des années 1940, la recherche des virus responsables de la poliomyélite a été à l'origine de la mise en évidence de nombreux autres entérovirus. La classification de 1957 répartissait les entérovirus alors connus en quatre groupes : les poliovirus, les coxsackievirus A et B et les echovirus [3] (figure 3). Au sein de chaque groupe, des tests de séroneutralisation permettaient de distinguer différents sérotypes : deux isolats appartenaient au même sérotype si les anticorps produits contre l'un neutralisaient l'autre. Si un virus n'était neutralisé par aucun des sérums de référence, un nouveau sérotype était créé dont il devenait le prototype contre lequel un sérum de référence était produit.

\section{Poliovirus}

Les poliovirus sont les agents étiologiques de la poliomyélite, une maladie probablement connue depuis l'Antiquité 


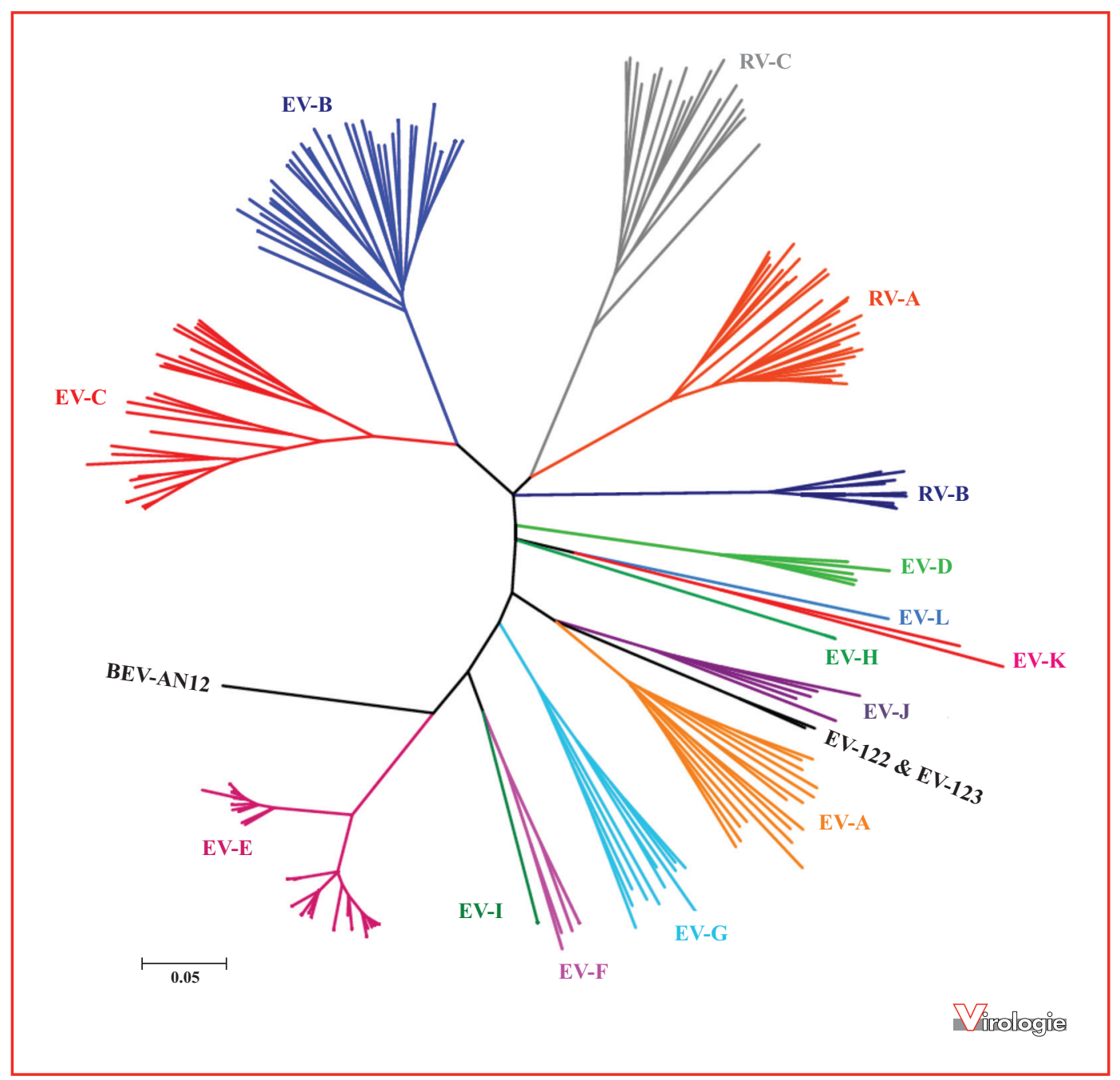

Figure 2. Arbre phylogénétique présentant les différentes espèces d'entérovirus (EV) et de rhinovirus (RV) aujourd'hui reconnues. L'arbre a été construit en utilisant les séquences peptidiques de la région $\mathrm{P} 1$. Certaines séquences détectées dans des échantillons bovins (BEV-AN12) et simiens (EV-122 et EV-123) n'appartiennent à aucune espèce existante.

comme en témoigne la stèle funéraire égyptienne montrant le prêtre Ruma avec une atrophie de la jambe droite qui évoque typiquement une séquelle de paralysie poliomyélitique (figure 4) [4, 5]. L'ancienneté de la poliomyélite en Égypte est également suggérée par l'existence de séquelles osseuses caractéristiques chez deux momies : celle du pharaon Minephtah Siptah (vers 1200 ans avant J.-C.) au musée du Caire, et celle d'un homme âgé (vers 3700 ans avant J.-C.) au musée archéologique de Philadelphie $[4,5]$. Le terme poliomyélite, dérivé des termes grecs «polios» (gris) et «myelos» (moelle) et du suffixe «-ite ( inflammation), fait référence au fait que la maladie résulte principalement de la destruction des neurones moteurs localisés dans la substance grise de la moelle épinière.
En 1909, le poliovirus a été identifié par Landsteiner, Popper et Levaditi $[6,7]$ comme étant l'agent étiologique de la poliomyélite paralytique aiguë en reproduisant la maladie chez le singe suite à l'injection par voie intrapéritonéale d'une suspension de moelle épinière d'un enfant ayant succombé à une poliomyélite sévère. Pendant de nombreuses années, le poliovirus n'était multiplié qu'in vivo chez le singe ; le processus d'extraction du virus était laborieux et le rendement très faible. Ce n'est qu'en 1949 qu'Enders $e t$ $a l$. [8] ont réalisé une percée scientifique majeure en réussissant à cultiver in vitro le poliovirus sur des cellules non nerveuses d'origine humaine, puis simienne. Ce progrès capital leur valut le prix Nobel en 1955 et fut à l'origine du développement de vaccins poliomyélitiques efficaces contre les trois sérotypes de poliovirus $[9,10]$. 


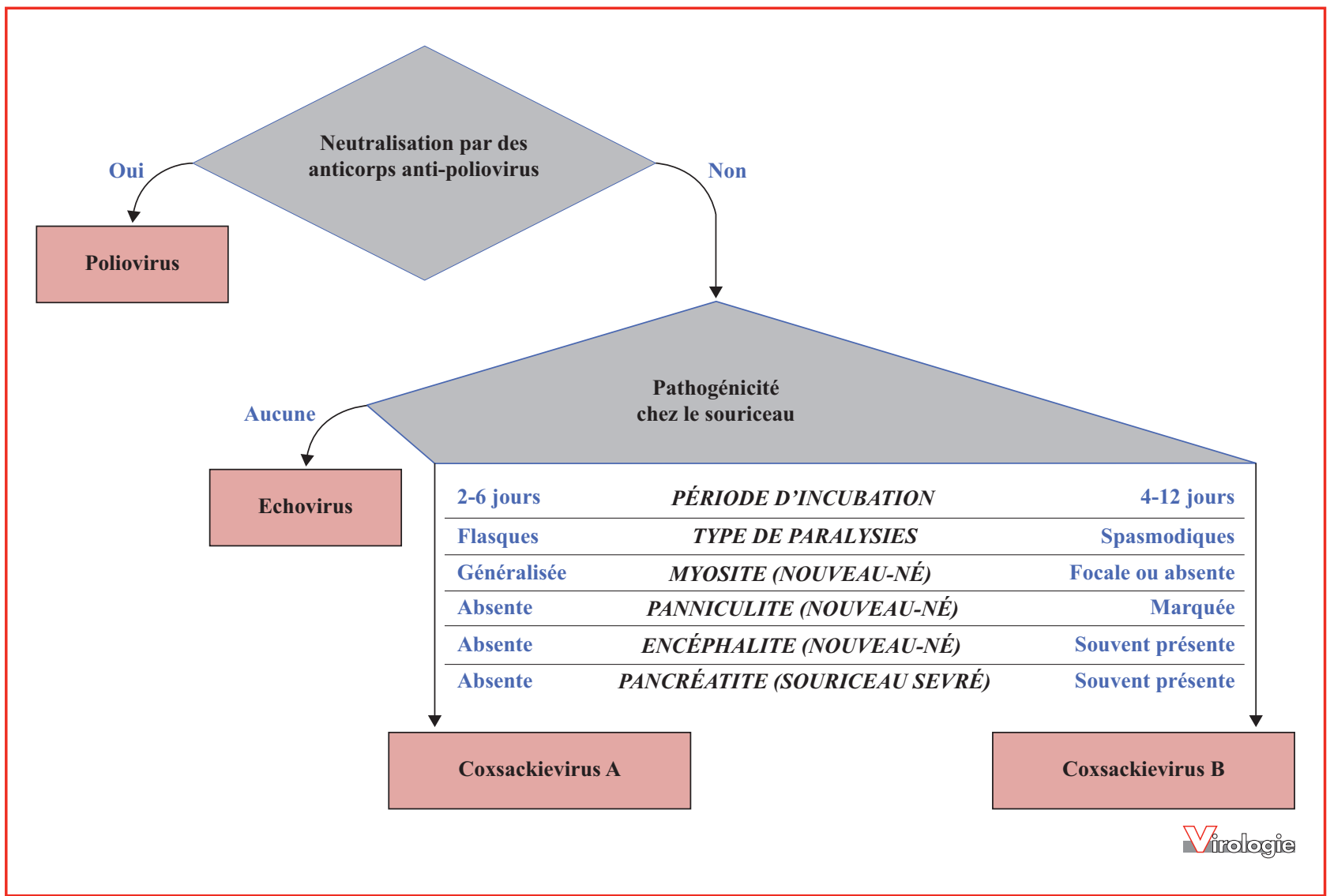

Figure 3. Logigramme de la classification des entérovirus en quatre groupes selon des critères phénotypiques. Ces critères se révèleront peu pertinents et ne seront plus utilisés à partir du début des années 1970.

\section{Coxsackievirus}

Les premiers coxsackievirus ont été isolés à Coxsackie, un village de l'État de New York aux États-Unis en 1948 par Dalldorf et Sickles [11] à partir des selles de deux enfants atteints de paralysie chez lesquels on soupçonnait une poliomyélite. Par la suite, les nouveaux coxsackievirus découverts ont été répartis dans deux groupes, A et B, d'après leur pouvoir pathogène chez le souriceau nouveauné (la souris adulte n'est pas sensible aux coxsackievirus) [12, 13] (figure 3).

Les coxsackievirus A (CV-A), quelle que soit la voie d'inoculation, provoquent chez le souriceau nouveau-né des paralysies flasques dues à une myosite généralisée à l'ensemble des muscles striés (y compris le muscle cardiaque) avec inflammation et nécrose des fibres musculaires. Des lésions rénales peuvent être également observées.

Inoculés par voie intracérébrale, les coxsackievirus B (CVB) provoquent des paralysies spasmodiques localisées, accompagnées d'ataxie et de tremblements. L'examen histologique montre une encéphalite nécrosante ainsi que des lésions musculaires focales, une atteinte du pancréas et du tissu graisseux, et occasionnellement une myocardite et une hépatite.

Vingt-quatre types de CV-A ont été distingués sur des critères sérologiques mais seuls 21 subsistent dans la classification actuelle : les types A15 et A18 ont été fusionnés avec les types A11 et A13, respectivement, et sont aujourd'hui obsolètes. Le type A23 s'est révélé sérologiquement indiscernable du type echovirus 9 [14] ; le type echovirus 9 ayant été découvert avant le type coxsackievirus A23, c'est le premier qui a été conservé, entraînant de fait l'inclusion d'un virus pathogène pour le souriceau au sein du groupe des echovirus défini justement d'après l'innocuité de ses membres pour le souriceau (cf. infra).

Seuls six types de CV-B ont été définis et tous ont, pour l'instant, survécu aux remaniements taxonomiques.

Chez l'homme, la majorité des infections à coxsackievirus sont inapparentes. Quand elles existent, les manifestations cliniques sont plus ou moins spécifiques et évoluent le plus souvent favorablement $[1,13]$. 


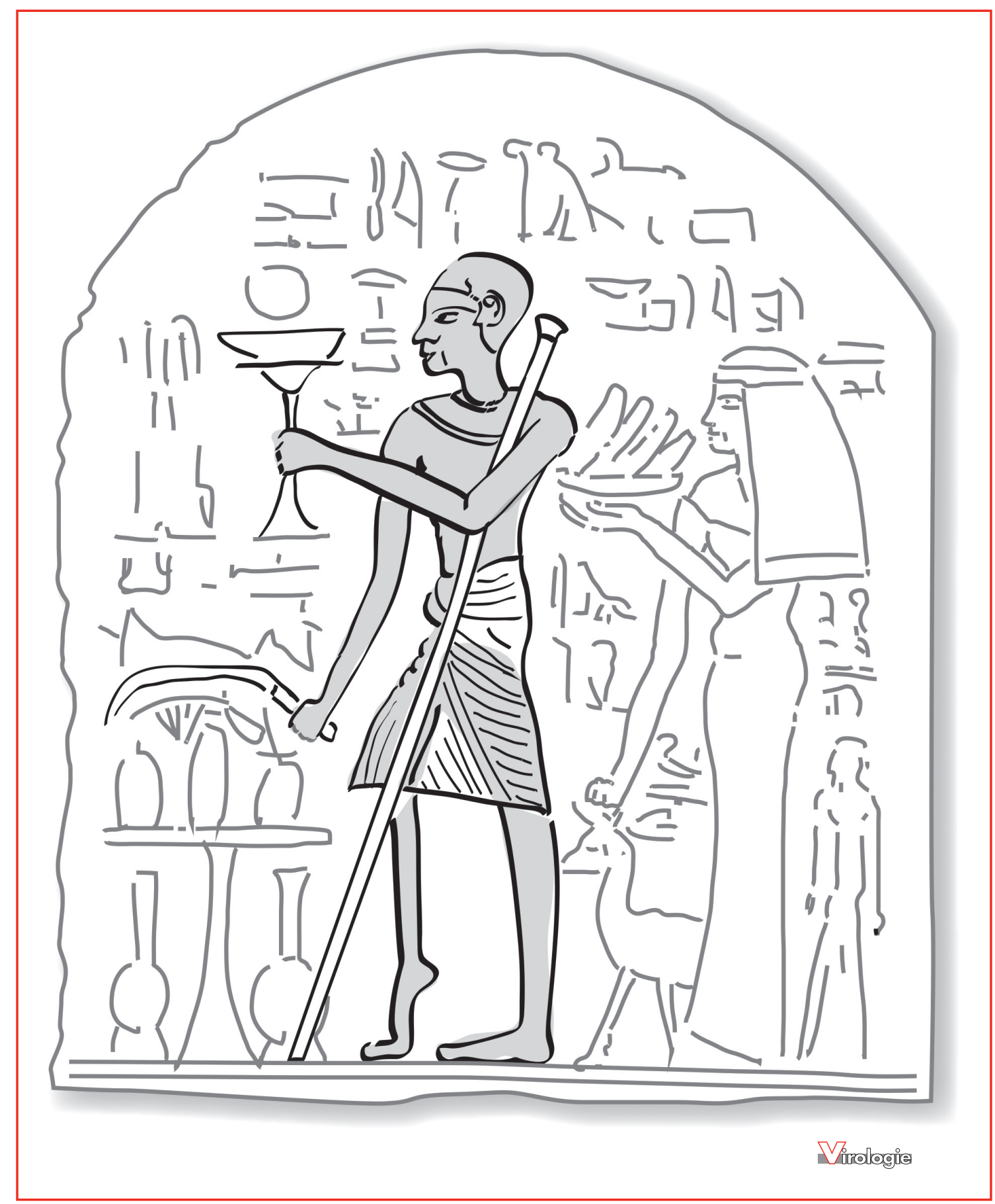

Figure 4. Stèle funéraire égyptienne dédiée à la déesse syrienne Astarté (environ 1350 ans avant J.-C.). La jambe gauche déformée du prêtre Ruma présente les séquelles caractéristiques de la poliomyélite paralytique dues à un déficit de stimulation musculaire et subséquemment une rétraction des muscles et du membre (Glyptothèque Ny Carlsberg de Copenhague).

\section{Echovirus}

Les echovirus ont été identifiés de manière fortuite par leur effet cytopathique sur des cellules primaires de rein de singe à partir de selles de malades atteints de méningite aseptique (souvent diagnostiquée comme poliomyélite non paralytique) et de selles d'enfants sains ou diarrhéiques. Distincts des coxsackievirus par leur innocuité chez les souriceaux (figure 3), ces virus ont été baptisés « echovirus » (pour 
Enteric Cytopathic Human Orphan viruses) car, n'étant alors associés à aucune maladie précise, ils étaient qualifiés d' « orphelins » [15]. La plupart des echovirus ne sont plus orphelins et ont été associés à un ou plusieurs syndromes cliniques depuis des maladies respiratoires mineures jusqu'à des affections du système nerveux central (méningites aseptiques) [13].

Au total, 34 types d'echovirus ont été distingués sur des critères sérologiques mais seuls 28 subsistent aujourd'hui : le type 8 est aujourd'hui considéré comme un variant du type 1 et le type 34 comme un variant du type coxsackievirus A24 [16] ; le type 28 a été inclus dans le groupe des rhinovirus sous le nom de rhinovirus 1A (cf. infra) [2] ; les types 22 et 23 ont donné naissance à un nouveau genre au sein de la famille Picornaviridae et ont été renommés Parechovirus 1 et 2 [17] tandis que le type 10 s'est révélé être un virus à $\mathrm{ARN}$ bicaténaire et a donné naissance à un nouveau genre (genre Orthoreovirus, famille Reoviridae) dont il est le prototype (Mammalian orthoreovirus 1).

\section{Les limites de la classification reposant sur le pouvoir pathogène des virus}

La classification des entérovirus non polio nouvellement découverts selon leur pouvoir pathogène chez le souriceau se révélait parfois impossible : comme l'illustrent les exemples des types coxsackievirus A23/echovirus 9 et coxsackievirus A24/echovirus 34 ( $c f$. supra), certains sérotypes comportaient à la fois des souches pathogènes et des souches non pathogènes pour le souriceau.

Par ailleurs, il n'existe pas de corrélation entre l'appartenance aux groupes coxsackievirus A, B ou echovirus et le type de manifestations cliniques chez l'homme. Certaines affections semblent n'être dues qu'à des virus appartenant à l'un des trois groupes sans toutefois que tous les sérotypes de ce groupe n'y soient forcément associés : - la pharyngite vésiculeuse, également appelée herpangine, est provoquée par certains coxsackievirus du groupe A ;

- le syndrome main-pied-bouche, également appelé stomatite vésiculeuse avec exanthème, peut également être dû à certains coxsackievirus du groupe A ;

- un variant particulier du coxsackievirus A24 a été impliqué dans de nombreuses épidémies de conjonctivite hémorragique aiguë du fait de son adaptation aux acides sialiques de la cornée qu'il utilise comme récepteur [18] ; - la pleurodynie, ou maladie de Bornholm, est une myalgie épidémique associée à des coxsackievirus du groupe $\mathrm{B}$;

- certains coxsackievirus du groupe B sont également responsables de cardiomyopathies dilatées et de myocardites chroniques et pourraient jouer un rôle dans le développement du diabète de type 1 .

D'autres affections, en revanche, peuvent être causées par des virus appartenant à des groupes différents : les cox- sackievirus des groupes A et B et des echovirus ont été incriminés dans des atteintes respiratoires hautes ou basses (rhume, bronchiolites) ; certains echovirus et coxsackievirus du groupe A, aussi bien que tous ceux du groupe B, peuvent être à l'origine d'atteintes du système nerveux central : la plus fréquente est la méningite lymphocytaire, avec fièvre puis raideur de la nuque caractéristique du syndrome méningé classique, dont l'évolution est toujours favorable. La distinction coxsackievirus A/coxsackievirus B/echovirus paraissant finalement peu pertinente pour la classification de ces virus, elle fut abandonnée au tournant des années 1960 et 1970. Depuis, les nouveaux types d'entérovirus identifiés reçoivent simplement un numéro dont l'attribution se fait par incrément au fur et à mesure de la découverte de nouveaux types. Soixante-sept types ayant été identifiés avant la mise en place de ce système (trois poliovirus, vingt-quatre coxsackievirus $\mathrm{A}$, six coxsackievirus B et trente-quatre echovirus), la numérotation débuta avec le numéro 68 , dont le prototype est la souche Fermon. L'entérovirus 72 n'existe plus car il se révèlera être un virus très différent des entérovirus : le virus de l'hépatite A.

Afin de conserver tout le bénéfice de l'abondante littérature publiée jusqu'alors dans le domaine, la commission en charge de la nomenclature des entérovirus décida de ne pas modifier le nom des types décrits avant la mise en place de ce nouveau système de numérotation. Les noms historiques des types les plus anciens (coxsackievirus, echovirus et poliovirus) ont ainsi perduré jusque dans la nomenclature actuelle.

Le système de numérotation suppose une centralisation de l'attribution des nouveaux numéros pour éviter les doublons. En pratique, les auteurs découvrant un virus divergeant des types connus sont invités à contacter le groupe d'étude des Picornaviridae du Comité international pour la taxonomie des virus (ICTV) pour obtenir la confirmation de l'originalité du nouveau type suspecté et pour qu'un numéro lui soit attribué. L'efficacité de ce processus n'est pas absolue puisqu'il existe quelques doublons ( $c f$. infra).

\section{Les rhinovirus}

Les premiers rhinovirus, isolés par David Tyrell au cours des années 1960 [19], ont été nommés ainsi à cause de leur adaptation à la région nasopharyngée. Ce sont les principaux agents responsables des rhinites et autres infections bénignes du nasopharynx [20]. Dans la classification de 1963 [2], les picornavirus d'origine humaine étaient divisés principalement en deux groupes : les entérovirus et les rhinovirus (un troisième groupe comprenait les picornavirus qui ne pouvaient pas être classés dans l'une ou l'autre des deux catégories précédentes). Le groupe des 
rhinovirus nouvellement créé incluait désormais les virus déjà nommés rhinovirus mais aussi des virus baptisés coryzavirus, murivirus ou virus Salisbury par leurs découvreurs ainsi que l'echovirus 28 qui fut choisi comme prototype du groupe [21]. Tous ces virus présentaient des propriétés physicochimiques et phénotypiques communes qui les distinguaient des autres entérovirus. En particulier, leur adaptation à la réplication dans le tractus nasopharyngé se traduisait au laboratoire par une multiplication préférentielle à $33^{\circ} \mathrm{C}$ (versus $37^{\circ} \mathrm{C}$ pour les autres entérovirus) et une sensibilité aux $\mathrm{pH}$ acides.

Précédemment, certains de ces virus avaient été regroupés sous le terme de ERC virus (pour ECHO 28-RhinovirusCoryzavirus) [22]. Cette terminologie ne fut pas retenue et il fut finalement choisi de renommer tous ces virus en adoptant un système de numérotation similaire à celui utilisé plus tard pour les entérovirus : 55 types de rhinovirus furent initialement définis (de rhinovirus 1 à rhinovirus 55), le prototype (ex-echovirus 28) devenant le rhinovirus 1A [23]. La dichotomie entérovirus/rhinovirus sera reprise par le premier rapport de l'ICTV qui créera deux genres distincts (Enterovirus et Rhinovirus) au sein de la famille Picornaviridae [24]. Plus tard, les classifications basées sur la phylogénie aboliront cette distinction et les deux genres seront fusionnés ( $c f$. infra).

\section{Les entérovirus non humains}

Dès les années 1950, des virus présentant des caractéristiques proches de celles des entérovirus humains ont été identifiés dans des échantillons de selles de différents animaux. Ainsi, plusieurs sérotypes de virus de primates non humains furent identifiés au cours des décennies suivantes. Au début des années 1980, il fut proposé de rationaliser leur taxonomie et d'utiliser pour chacun le terme Simian enterovirus suivi d'un numéro d'ordre de 1 à 18 [25]. De même, plusieurs sérotypes de virus identifiés comme des entérovirus furent trouvés chez les porcins et les bovins et nommés Porcine enterovirus 1 à 11 et Bovine enterovirus 1 et 2 .

La classification basée sur la phylogénie aboutira progressivement à la disparition de cette nomenclature et à la redistribution de ces virus dans de nouvelles espèces (cf. infra).

\section{Les limites du sérotypage}

Les premières classifications des entérovirus et des rhinovirus reposaient sur le concept de sérotypes : l'ensemble des virus présentant entre eux des profils de séroneutralisation réciproque forment un sérotype tandis que deux virus appartenant à des sérotypes différents ne montrent pas de neutralisation croisée. Le sérotypage des entérovirus repose sur des expériences de séroneutralisation utilisant un panel de sérums provenant d'animaux immunisés par l'un des sérotypes connus. Chaque nouveau virus à typer devait être testé en utilisant l'ensemble des sérums du panel pour déterminer son sérotype ; s'il n'était neutralisé par aucun sérum, il appartenait probablement à un sérotype inconnu. Cette démarche devint de plus en plus fastidieuse au fur et à mesure de la découverte de nouveaux sérotypes qui augmentait le nombre de sérums à tester sur chaque virus à caractériser. Afin de réduire la charge de travail, des méthodes reposant sur des mélanges de sérums furent développées au tournant des années 1950-1960 [26, 27] : la constitution ingénieuse de ces mélanges permettait de déterminer le sérotype d'un virus sans avoir à tester individuellement les sérums développés contre chaque sérotype (figure 5). Cette approche permettait une réduction substantielle de la charge de travail mais nécessitait toutefois la production d'importants volumes des mélanges standardisés de sérums (d'où l'utilisation de chevaux pour les immunisations) et leur distribution à tous les laboratoires désirant effectuer le sérotypage [28]. De plus, la découverte régulière de nouveaux sérotypes obligeait à concevoir de nouveaux mélanges [29, 30].

Malgré l'utilisation de ces mélanges, la séroneutralisation restait une technique présentant de nombreuses limites. En premier lieu, elle imposait l'isolement en culture cellulaire du virus à caractériser. En outre, elle se révélait infructueuse dans le cas d'échantillons contenant plusieurs sérotypes d'entérovirus, situation relativement fréquente qui nécessitait la séparation des virus par la technique des plages de lyse. Enfin, le sérotypage était parfois compliqué par l'existence de variants antigéniques faiblement neutralisés par les sérums produits contre les souches de référence. En particulier, les souches dites «prime » sont caractérisées par des profils de neutralisation non réciproques : une souche prime n'est pas neutralisée par le sérum produit avec la souche de référence mais le sérum produit avec la souche prime neutralise la souche de référence aussi efficacement que la souche prime.

Réservées à des laboratoires experts, fastidieuses et peu adaptées à l'analyse d'un grand nombre d'isolats, les techniques de séroneutralisation des entérovirus donnaient au final des résultats peu satisfaisants et faiblement reproductibles d'un laboratoire à l'autre [31]. Elles furent supplantées par les techniques de typage moléculaire développées au cours des années 2000.

\section{Classifications basées sur la séquence génomique}

Le typage moléculaire est à la base de la classification actuelle. Il repose sur la corrélation qui existe entre les 


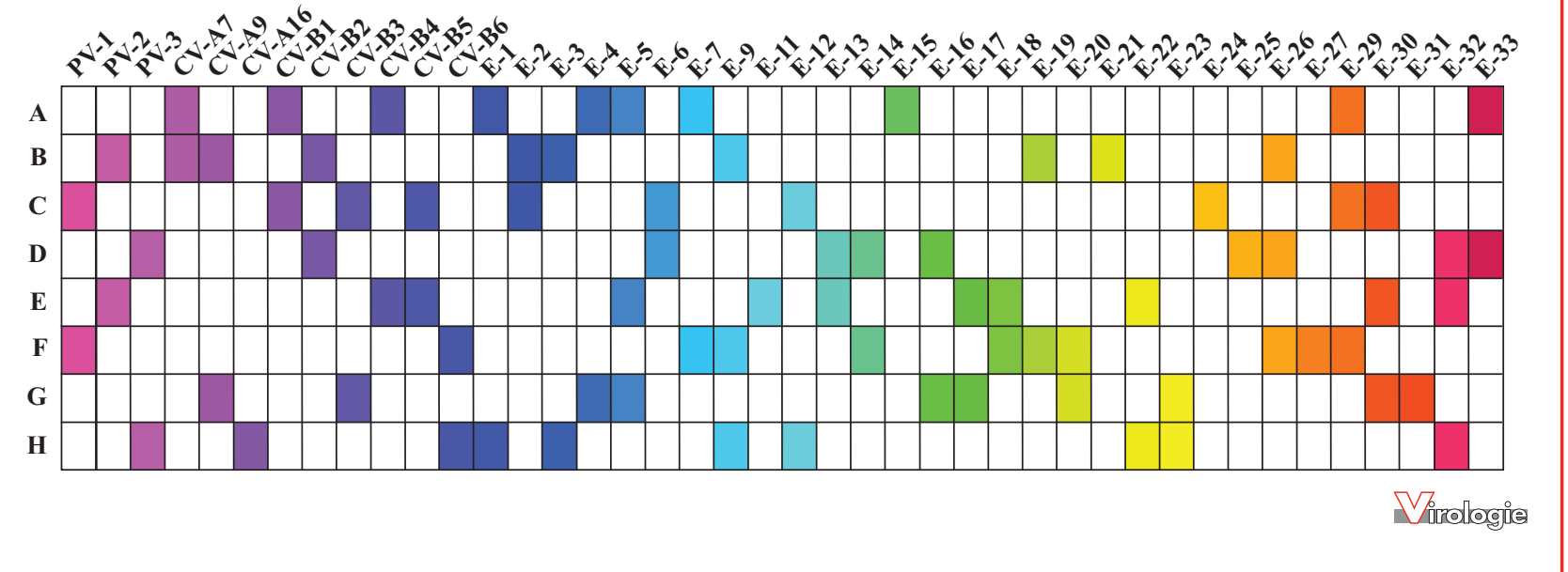

Figure 5. Composition de mélanges de sérums conçus dans les années 1960 pour le sérotypage des entérovirus. Ces mélanges sont couramment appelés pools LBM (pour Lim et Benyesh-Melnick). Chaque mélange $(A$ à $H)$ est caractérisé par la présence (en couleur) ou l'absence (en blanc) des différents sérums équins produits contre chacun des sérotypes de poliovirus (PV), coxsackievirus $A$ (CV-A) et $B(C V-B)$ et d'echovirus (E). Les mélanges sont conçus pour que chaque combinaison de résultats positifs soit unique. Ainsi, un virus neutralisé par les mélanges $B$ et $E$ ne peut être qu'un PV-2 puisque seul le sérum anti-PV-2 est commun à ces deux mélanges. Un virus donnant un résultat positif avec les mélanges $D$ et $E$ peut être un E-13 ou un E-32 mais le résultat obtenu avec le mélange $H$ permet de distinguer ces deux virus. Cette méthode permet d'identifier 42 sérotypes avec seulement huit mélanges de sérums. Elle est toutefois inopérante lorsque plusieurs sérotypes sont présents dans le même échantillon.

sérotypes et les séquences nucléotidiques qui codent la capside, notamment la région codant la protéine VP1 [32] : les entérovirus étant des virus non enveloppés, c'est contre la capside que sont dirigés la majorité des anticorps produits contre ces virus, en particulier les anticorps neutralisants. Ainsi, la classification génétique est globalement cohérente avec la classification originelle basée sur les relations sérologiques entre les virus : deux virus génétiquement proches entraînent généralement des réactions sérologiques croisées et vice versa [32-34]. La classification actuelle ignore totalement la diversité génétique des régions non traduites et des régions codant les protéines non structurales qui connaissent pourtant un brassage génétique important dû aux événements de recombinaison, particulièrement fréquents entre entérovirus co-circulants ; dans cette classification, seule la séquence de la capside confère son identité à un virus.

De nombreuses méthodes d'amplification à large spectre ont été développées pour amplifier par RT-PCR de courtes séquences génomiques dans la région de la capside [3537]. Pour les entérovirus humains des espèces $\mathrm{A}$ à $\mathrm{D}$, la méthode la plus communément utilisée a été développée par les CDC d'Atlanta [38] et permet d'amplifier par RTPCR semi-nichée un fragment d'environ 300 nucléotides au début de la région codant la protéine VP1. Cette méthode est particulièrement sensible et permet le typage de virus directement dans les échantillons cliniques sans nécessité de réaliser un isolement sur lignées cellulaires. Elle constitue la méthode actuellement recommandée par les lignes directrices sur la surveillance des entérovirus de l'Organisation mondiale de la santé.

Le séquençage des amplicons obtenus permet le typage des virus ainsi analysés. Les séquences sont comparées aux séquences de virus de référence pour déterminer à quel type appartient un virus donné ; un virus présentant une séquence de capside divergeant significativement des séquences déjà connues constitue un nouveau type. Le seuil de divergence nécessaire pour considérer que deux virus appartiennent à des types différents est difficile à définir de façon définitive car il dépend de l'espèce considérée et de la région du génome utilisée pour le typage. Dans la région codant la protéine VP1, des seuils de $25 \%$ de divergence au niveau nucléotidique et $15 \%$ au niveau peptidique constituent une bonne approximation de première intention mais demandent à être affinés en fonction du contexte $[32,39]$. Des outils en ligne ont été développés pour permettre le typage de virus en comparant automatiquement les séquences soumises à des séquences de référence [40, 41]. La classification basée sur le sérotypage et celle basée sur le génotypage sont globalement superposables. Cependant, la classification basée sur le génotypage a permis de montrer que certains sérotypes distincts étaient en réalité très proches, voire indiscernables, génétiquement. Ainsi, les sérotypes CV-A11 et CV-A15, d'une part, et CV-A13 et CV-A18, d'autre part, ne forment aujourd'hui que deux génotypes (CV-A11 et CV-A13), les types CV-A15 et 


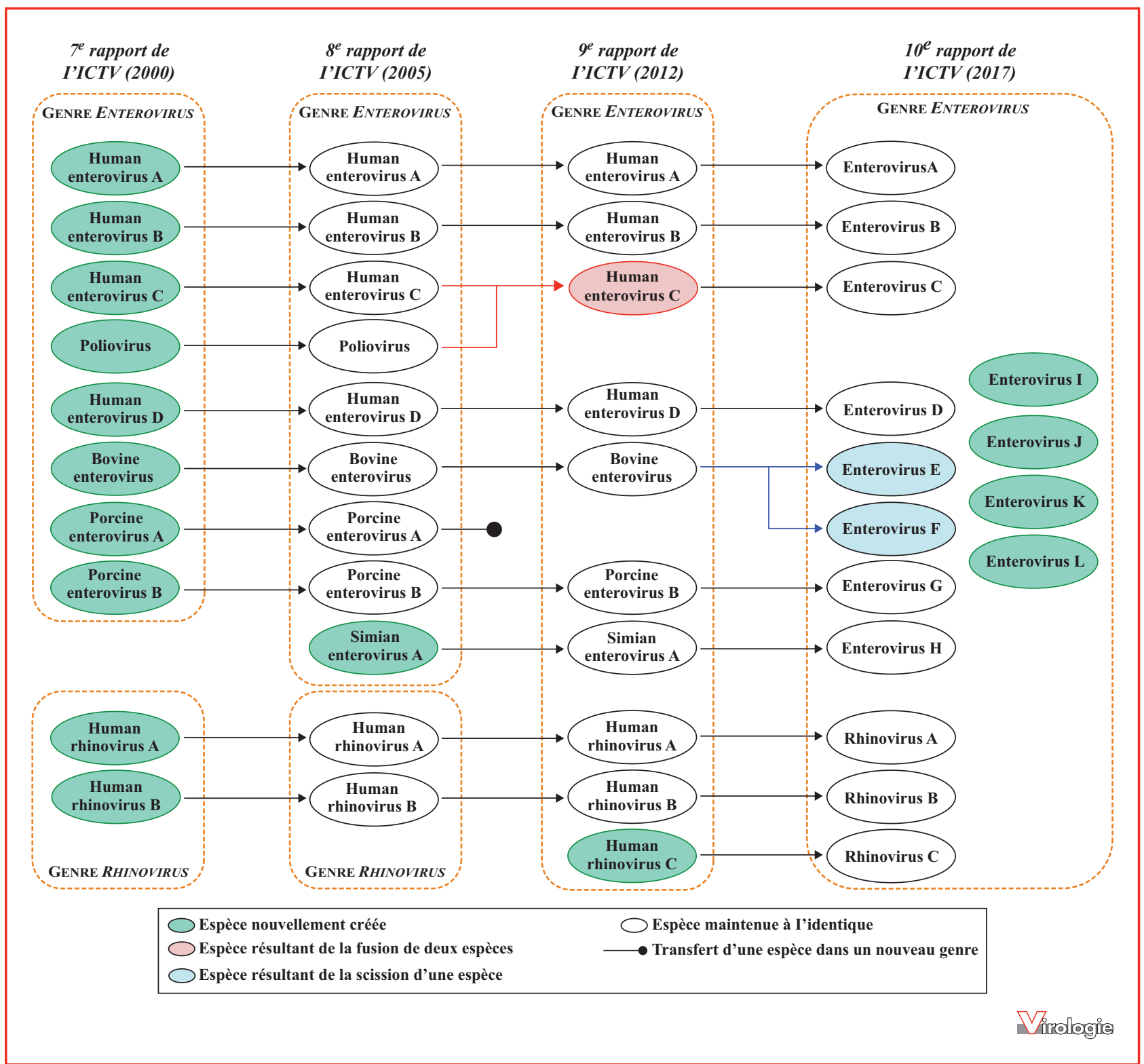

Figure 6. Évolution de la composition des genres Enterovirus et Rhinovirus depuis le septième rapport de l'ICTV qui, pour la première fois, regroupa différents sérotypes en espèces.

CV-A18 n'étant respectivement que des variants antigéniques de CV-A11 et de CV-A13. À l'inverse, certaines souches du sérotype $\mathrm{CV}$-A24 relativement distantes génétiquement des CV-A24 de référence ont donné naissance à un nouveau type défini sur des critères génétiques (EV-C99) [42]. Les bases de données de séquences étant rarement corrigées pour tenir compte de ces évolutions, les remaniements opérés au cours du temps peuvent entraîner des quiproquos concernant l'identité d'une souche. En particulier, il convient d'être prudent lors de l'utilisation d'outils tels que BLAST pour identifier une séquence de terrain et de vérifier que le type des virus présentant la plus forte homologie de séquence avec la souche à identifier n'a pas changé de nom depuis le dépôt des séquences de ces virus dans les bases de données.

La classification basée sur les séquences génétiques de capsides a conduit l'ICTV à redistribuer dans son septième rapport (2000) les entérovirus dans huit nouvelles espèces définies sur des critères phylogénétiques au sein du genre Enterovirus (figure 6). Cette nouvelle classification a 
entraîné la répartition des différents types de coxsackievirus $\mathrm{A}$ dans trois espèces, l'ensemble des coxsackievirus $\mathrm{B}$ et des echovirus étant rassemblés dans l'espèce Human enterovirus B (figure 7).

Malgré son apparente cohérence, cette nouvelle classification était toutefois imparfaite. Tout d'abord, elle conservait (sans doute pour des raisons historiques) l'espèce Poliovirus malgré la proximité génétique de ces virus avec les membres de l'espèce Human enterovirus $C$; les poliovirus ne seront reconnus membre de l'espèce $\mathrm{C}$ qu'en 2008 [43]. Par ailleurs, en conservant une référence à l'hôte principal des virus, elle créait de nouvelles incohérences. Ainsi, les espèces Human enterovirus $A$ incluait des virus typiquement simiens (SV19, SV43, SV46 et baboon enterovirus A13) tandis que l'espèce Human enterovirus $B$ contenait le type simien SA5 et des lignages de coxsackievirus B4 et B5 circulant chez le porc et initialement appelés Swine Vesicular Disease Virus types 1 et 2 [44]. Ces ambiguïtés ont été levées par l'abandon en 2013 de toute mention relative à l'hôte dans le nom des espèces (figure 6) [45]. Ce changement s'accompagne de l'ajout du nom de l'espèce dans l'abréviation de celui du type. Ainsi, l'abréviation utilisée pour l'entérovirus 71 passe de HEV-71 à EV-A71. Cet ajout permet d'identifier immédiatement l'espèce à laquelle appartient un type donné et de lever les ambiguïtés dues aux doublons de numérotation évoqués plus haut : EV-B111/EV-D111 [46, 47], EV-B112/EV-J112 [48, 49], EV-B113/EV-C113 [48, 50], EV-A120/EV-D120 [51, 52] et EV-A121/EV-J121 [53, 54]. L'ajout du nom de l'espèce dans le nom du type peut toutefois créer une nouvelle confusion puisqu'il ne concerne pas les coxsackievirus : si tous les CV-B appartiennent à l'espèce $\mathrm{B}$, certains $\mathrm{CV}$-A appartiennent aux espèces $\mathrm{B}$ et $\mathrm{C}$ (figure 7). La modification du nom de ces virus a été évoquée : par exemple, le CV-A9 (membre de l'espèce $\mathrm{B}$ ) deviendrait $\mathrm{CV}$-B9 tandis que le CV-A11 (membre de l'espèce $\mathrm{C}$ ) deviendrait CV-C11. Cette modification n'a pas été retenue.

Les modifications de 2013 n'ont pas bouleversé la taxonomie des virus des anciennes espèces HEV-A à -D. Elles ont, en revanche, largement modifié le nom des virus des espèces Bovine enterovirus, Porcine enterovirus B et Simian enterovirus A (figure 6). Ces espèces ont été renommées Enterovirus $E, F, G$ et $H$ (l'espèce Bovine enterovirus ayant été scindée en deux). Au sein de chaque espèce, les types ont été renumérotés en commençant par le type 1 (EV-E1, EV-F1, etc.). Par exemple, le type PEV-9 (pour Porcine enterovirus 9) est devenu EV-G1 (pour Enterovirus G1). Comme évoqué plus haut, ces changements rendent obsolètes les noms associés aux séquences déposées précédemment dans les bases de données publiques.

Par ailleurs, l'organisation génomique similaire des rhinovirus et des entérovirus, leur proximité génétique relative au sein de la famille Picornaviridae et le fait que les espèces connues de rhinovirus et d'entérovirus ne forment pas deux groupes monophylétiques distincts conduisirent les taxonomistes à fusionner en 2008 les genres Rhinovirus et Enterovirus. Les deux espèces de rhinovirus existant alors (Human rhinovirus A et Human rhinovirus B) furent incluses dans le genre Enterovirus et le genre Rhinovirus disparut du neuvième rapport de l'ICTV (figure 6) [43]. Une troisième espèce (Human rhinovirus $C$ ) fut créée en 2009 pour regrouper les nombreux types de rhinovirus découverts à partir du milieu des années 2000 et n'appartenant pas aux deux espèces précédentes $[55,56]$. Cette espèce compte aujourd'hui plus d'une cinquantaine de types. L'adjectif Human fut abandonné en 2012 pour donner naissance aux espèces actuelles Rhinovirus $A, B$ et $C$.

La disparition du genre Rhinovirus et l'inclusion de ses membres au sein du genre Enterovirus crée une ambiguïté déroutante induite par l'étymologie des mots rhinovirus et entérovirus : il paraît sans doute difficile aux nonspécialistes de comprendre pourquoi les rhinovirus, virus des voies respiratoires, sont classés dans l'espèce Enterovirus. Même la frontière entre virus entériques et virus respiratoires est difficile à établir puisque les EV-D68 (membre de l'espèce Enterovirus $D$ ) ont des caractéristiques de rhinovirus : ce sont des virus qui se répliquent mieux à $33^{\circ} \mathrm{C}$ qu'à $37^{\circ} \mathrm{C}$, ils perdent leur infectiosité lorsqu'ils sont soumis à des $\mathrm{pH}$ acides et ils sont responsables de syndromes respiratoires [57] ; un isolat clinique d'EV-D68 avait d'ailleurs été initialement identifié comme un nouveau type de rhinovirus (HRV-87) [58]. Par ailleurs, plusieurs nouveaux types d'EV-C ont récemment été découverts dans des échantillons rhinopharyngés de patients présentant des symptômes respiratoires [59-61].

Pour éviter cet écueil, certaines propositions avaient été faites pour renommer le genre regroupant les entérovirus et les rhinovirus (Rhenterovirus, Rhinenterovirus...). Impliquant sans doute des changements trop importants, cette modification n'a pour l'heure pas été retenue. Elle pourrait d'ailleurs être prise en défaut dans le futur par la découverte de nouveaux virus appartenant à ce genre mais n'ayant ni les caractéristiques des virus entériques, ni celles des virus respiratoires.

Actuellement, on distingue 15 espèces au sein du genre Enterovirus (figure 6). Les critères utilisés pour déterminer si un ensemble de virus forment une seule espèce sont principalement des critères génétiques : des virus appartiennent à une espèce commune s'ils ont une organisation génomique identique, si les pourcentages de GC de leurs génomes ne diffèrent pas de plus de 2,5 points, s'ils partagent plus de $70 \%$ d'identité peptidique sur toute la polyprotéine et sur les protéines $2 \mathrm{C}$ et $3 \mathrm{CD}$ et plus de $60 \%$ d'identité peptidique dans la capside. 


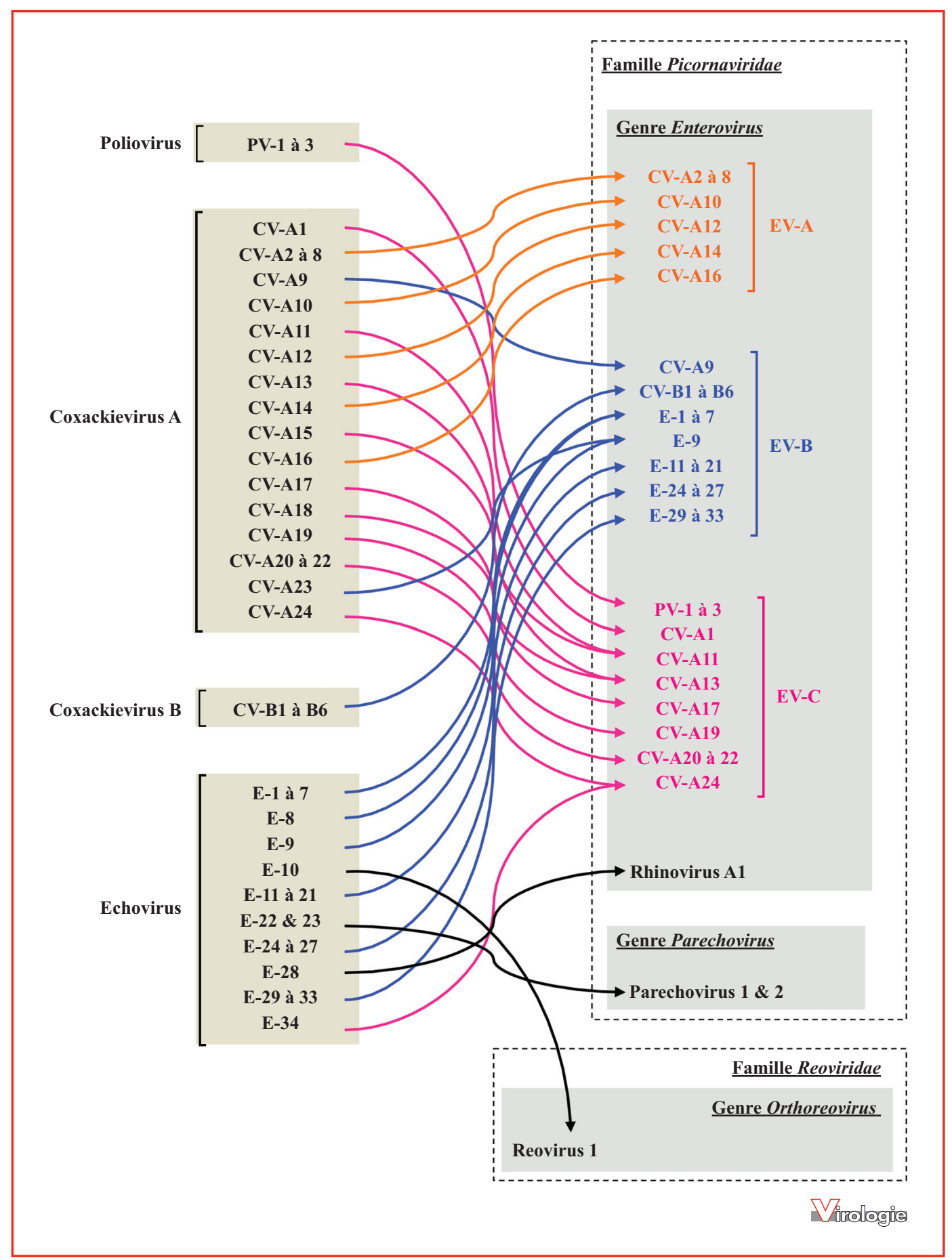

Figure 7. Répartition des différents sérotypes de coxsackievirus $A$ et $B$ (CV-A et $B$ ), de poliovirus (PV) et d'echovirus (E) dans la classification actuelle. Certains sérotypes n'apparaissent plus dans la classification actuelle : plusieurs d'entre eux ont été réunis deux à deux sous le même nom (CV-A11 et CV-A15, CV-A13 et CV-A18, CV-A23 et E-9, CV-A24 et E-34, E-1 et E-8), d'autres ont été renommés (flèches noires). 
Il existe également des critères phénotypiques : des virus appartenant à une même espèce doivent notamment infecter un nombre limité d'espèces-hôtes et utiliser un spectre étroit de récepteurs de l'hôte. En réalité, ces critères paraissent très difficiles à évaluer, même pour les virus infectant l'homme qui sont pourtant les mieux caractérisés : on connaît presque une centaine de types d'EV-A à D infectant l'homme mais les récepteurs qu'ils utilisent ne sont identifiés que pour quelques-uns d'entre eux et sans doute pas de façon exhaustive.

Certaines espèces ne sont connues que par quelques séquences génétiques, comme l'espèce EV-I dont il n'existe que deux génomes complets séquencés à partir de selles de dromadaires et dont aucun membre n'a jamais été isolé [62]. L'existence de séquences génétiques relativement éloignées des espèces connues laisse présager l'augmentation prochaine du nombre d'espèces. Les nouvelles techniques de séquençage profond et le criblage d'échantillons provenant d'espèces animales chez lesquelles la présence d'entérovirus n'a jamais été étudiée entraîneront probablement dans le futur la découverte de très nombreuses espèces aujourd'hui inconnues. L'analyse phylogénétique détaillée de la masse de données de séquences ainsi générées constituera probablement un défi pour les taxonomistes.

\section{Clades, clusters, génogroupes, génotypes, lignages, sous-types, variants, etc.}

Au sein des types, les analyses phylogénétiques permettent généralement d'observer des groupes distincts constitués de séquences relativement proches entre elles à l'échelle du type considéré. Plusieurs appellations sont utilisées pour nommer ces groupes sans qu'il existe de définition précise des différents termes utilisés. Par exemple, les EV-A71 sont généralement répartis en génogroupes (différenciés par des lettres) tandis que les CV-A24 sont classés en génotypes (différenciés par des chiffres romains) et les EV-D68 en clades (différenciés par des lettres). Ces différentes terminologies ne reflètent aucune différence biologique ou phylogénétique mais découlent simplement d'une habitude qui est généralement fixée par les premiers travaux s'intéressant à la phylogénie du type considéré.

Les critères phylogénétiques retenus pour définir les groupes au sein des types ne sont pas non plus définis de façon absolue. Ils dépendent bien sûr de la variabilité intratypique du type considéré mais aussi du nombre de séquences connues ou de la région génomique considérée. Les groupes ainsi définis ne font donc l'objet d'aucune validation officielle par l'ICTV. Ceci peut créer une certaine confusion lorsque des auteurs utilisent une nomenclature qui ne tient pas compte de nomenclatures précédemment établies et génèrent ainsi des nomenclatures concurrentes. Il arrive également que des auteurs annoncent l'existence de nouveaux groupes dont la nouveauté ne repose que sur des critères à la pertinence douteuse.

La classification infratypique est donc une matière difficile : lorsque peu de séquences sont disponibles, cette classification repose sur peu d'informations et le risque de sur-interprétation est grand ; au contraire, lorsque des centaines, voire de milliers, de séquences sont à considérer, elle requiert une analyse exhaustive et minutieuse des séquences et de la bibliographie afférente et demande un travail considérable.

\section{Limites de la classification basée sur des critères génétiques}

Comparé au sérotypage, le typage moléculaire offre de nombreux avantages : il est beaucoup plus rapide, il permet de typer des virus présents sous forme de mélange (au prix toutefois du clonage des amplicons à séquencer en cas de séquençage avec la technique de Sanger) et il peut être conduit directement sur des échantillons cliniques ou environnementaux sans nécessité de recourir à l'isolement des virus. Il a d'ailleurs permis de découvrir de nombreux types de virus non cultivables, notamment les rhinovirus $\mathrm{C}$.

Cependant, le typage moléculaire n'est pas exempt de défauts. En premier lieu, il est parfois difficile de déterminer précisément les limites d'un génotype car les divergences intratypiques varient sensiblement d'un type à l'autre [63] . On ne sait pas si l'apparente hétérogénéité de la diversité intratypique reflète une réalité biologique c'est-à-dire une dérive génétique de la région codant la capside dont la vitesse varierait d'un type à l' autre sous l'effet de processus endogènes (taux d'erreur de la polymérase virale, taille de la progénie) ou exogènes (pression de sélection plus ou moins forte, co-circulation de variants antigéniques proches); cette hétérogénéité pourrait en fait n'être qu'une illusion due à un biais d'échantillonnage, certains types étant plus fréquemment observés ou observés dans un plus grand nombre de régions géographiques que d'autres. Ainsi, la diversité intratypique des EV-A71 avait été largement sousestimée jusqu'à la découverte de lignages inédits dont la circulation semble circonscrite à l'Inde, à l'Afrique subsaharienne ou à Madagascar [64, 65].

Le biais d'échantillonnage est d'ailleurs criant lorsque l'on consulte les bases de données de séquences : certains types ne sont connus que par quelques souches tandis que des milliers de séquences sont disponibles pour d'autres [63]. Les virus les plus représentés dans les bases de données sont bien évidemment les virus infectant l'homme et parmi ceux-ci les virus les plus pathogènes. En permettant la mise en évidence de virus non cultivables ou de virus minoritaires 


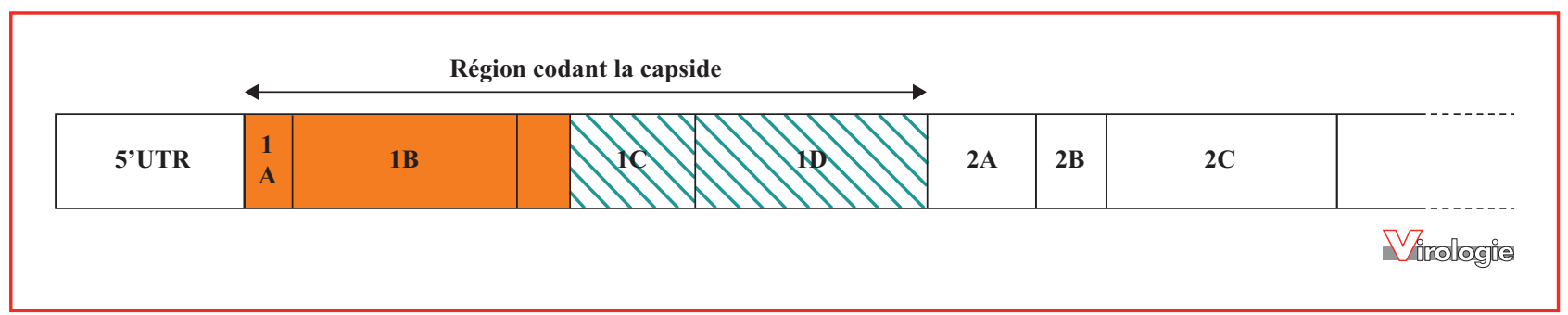

Figure 8. Organisation de la région codant la capside de la souche SE-03-7816. Le génome de cette souche est issu d'un événement de recombinaison entre un CV-B3 (en orange) et un CV-B4 (hachuré en vert). Le point de recombinaison est localisé au sein de la région $1 \mathrm{C}$ qui code la protéine VP3.

dont la présence était jusqu'alors masquée, l'amélioration de la sensibilité des techniques de RT-PCR et le développement du séquençage profond ont accéléré le rythme auxquels de nouveaux lignages, de nouveaux types ou de nouvelles espèces sont découverts. En comblant les espaces vides observés dans les arbres phylogénétiques, ces nouvelles données nous procureront un aperçu plus exhaustif de la diversité génétique des entérovirus mais elles risquent aussi de révéler un continuum de séquences au sein duquel il sera encore plus difficile de tracer des frontières claires [66]. Une autre limite du typage moléculaire est le fait que nous ignorons si des virus appartenant à un même génotype appartiennent toujours à un même sérotype : deux virus présentant des capsides (et notamment des protéines VP1) proches sont considérés comme appartenant à un même type et sont supposés appartenir à un même sérotype. La congruence entre génotypes et sérotypes a été validée au début des années 2000 sur les types alors connus [32] mais son caractère systématique n'a été que rarement réévalué depuis, notamment pour les types nouvellement découverts. Les relations sérologiques entre les virus constituent pourtant une réalité biologique certaine qui est déterminante pour le développement de vaccins ou pour comprendre la transmission interhumaine des virus. Pour les sérotypes connus depuis longtemps, la dérive génétique fait que les séquences codant la capside des souches actuelles sont relativement éloignées de celles des souches de référence isolées il y a plus de 50 ans [63]. Toutefois, une grande diversité nucléotidique ne se traduit pas forcément par une grande diversité peptidique : par exemple, les virus du type CV-A13 présentent dans la séquence codant la VP1 une diversité génétique particulièrement élevée mais la diversité peptidique de cette protéine au sein des CV-A13 reste du même ordre que celle observée au sein des autres types d'entérovirus C [63]. De même, des expériences de neutralisation menées dans notre laboratoire ont montré que des EV-A71 des génogroupes africains E et F étaient efficacement neutralisés par des sérums de patients infectés par des EV-A71 appartenant à d'autres génogroupes (Delpeyroux et Volle, données non publiées).
Un autre écueil du génotypage basé sur la séquence codant la capside pourrait venir de l'existence de souches d'entérovirus présentant une capside chimérique issue d'événements de recombinaison entre deux virus de types différents. Ainsi, une souche possédant une capside issue de la recombinaison d'un CV-B3 et d'un CV-B4 a été décrite par nos collègues de Saint-Étienne il y a une dizaine d'années [67]. Alors que cette souche possède une protéine VP1 provenant d'un CV-B4 (figure 8), elle est neutralisée par un sérum anti-CV-B3 mais pas par un sérum anti-CV-B4. Cependant, les souches à capside chimérique semblent extrêmement rares et, à l'exception notable de celle décrite ci-dessus, les points de recombinaison observés dans la région codant la capside se situent généralement à proximité de ses extrémités [68] ; les capsides codées par ces séquences recombinantes sont donc quasitotalement homotypiques à l'exception de quelques résidus d'aminoacides N- ou C-terminaux.

Enfin, en se focalisant sur la capside, la classification actuelle ignore la diversité génétique existant dans les régions non codantes et non structurales du génome. Du fait des événements de recombinaison, très fréquents au sein des populations d'entérovirus, deux virus peuvent avoir des génomes identiques dans la région codant la capside mais relativement divergents dans les autres régions. La capside est évidemment un indicateur fort de l'identité d'un entérovirus puisqu'elle est le déterminant principal de l'immunogénicité du virion et de son tropisme ; cependant, les régions non structurales et non codantes du génome modulent les propriétés phénotypiques des entérovirus [69] et jouent probablement un rôle dans leur histoire naturelle et leur pathogénicité. La classification actuelle des entérovirus est donc plutôt une classification de virions (c'est-à-dire de particules physiques) plutôt qu'une classification de virus (c'est-à-dire d'entités « vivantes » interagissant avec leur environnement). En facilitant l'obtention de séquences génétiques complètes d'entérovirus, les techniques de séquençage à haut débit conduiront peut-être à l'apparition de classifications prenant en compte l'ensemble du génome et non plus seulement la région codant la capside. 


\section{Conclusion}

Tout système taxonomique découle des connaissances et des paradigmes de l'époque à laquelle il est établi. La nécessité de modifier régulièrement la classification et la nomenclature des entérovirus reflète l'évolution de nos connaissances concernant ces virus mais surtout l'étendue de notre ignorance.

Réformer un système taxonomique n'est pas une tâche aisée. À chaque refonte, il est nécessaire de trouver un équilibre entre la cohérence du nouveau système proposé et la conservation de liens avec les systèmes précédents. Ces liens sont en effet indispensables pour garantir la compréhension des publications rédigées à l'époque où un système abandonné était utilisé. Dans le cas des entérovirus, la taxonomie est gérée par un petit groupe de personnes animé notamment par le professeur Nick Knowles. Celui-ci tient à jour un site dédié à ce sujet (http://www.picornaviridae.com). Ce site constitue une mine d'informations précieuses sur les entérovirus et les autres picornavirus et permet de suivre l'évolution de la nomenclature et de la taxonomie de ceux-ci. Ce suivi sera facilité par le choix de l'ICTV de remplacer la publication de ses rapports sous forme de gros volumes par un site Internet régulièrement mis à jour (https://talk.ictvonline.org).

Liens d'intérêts : les auteurs déclarent ne pas avoir de lien d'intérêt en rapport avec cet article.

\section{Références}

1. Tapparel C, Siegrist F, Petty TJ, Kaiser L. Picornavirus and enterovirus diversity with associated human diseases. Infect Genet Evol $2013 ; 14: 282-93$.

2. Melnick JL, Cockburn WC, Dalldorf G, Gard S, Gear JHS, Hammon WM, et al. Picornavirus group. Virology 1963; 19: 114-6.

3. Melnick JL, Cockburn WC, Dalldorf G, Gard S, Gear JHS, Hammon $\mathrm{WM}$, et al. The Enteroviruses. American Journal of Public Health and the Nations Health 1957 ; 47 : 1556-66.

4. Slomann HC. Contribution à la paléo-pathologie égyptienne. Bulletins et Mémoires de la Société d'anthropologie de Paris 1927 ; VII ${ }^{\circ}$ Série, Tome 8, fascicule 1-31927: 62-86.

5. Chastel C. Quand les momies égyptiennes nous parlent des infections qui les tourmentaient. Histoire des Sciences Médicales 2004 ; 2 : 147-55.

6. Landsteiner K, Popper E. Ubertragung der poliomyelitis acuta auf affen. Zeitschr. Immunitätsforsch 1909;2:377-90.

7. Landsteiner $\mathrm{K}$, Levaditi C. La transmission de la paralysie infantile aux singes. C R Soc Biol 1909; 67: 592-4.

8. Enders JF, Weller TH, Robbins FC. Cultivation of Lansing strain of poliomyelitis virus in culture of various human embryonic tissues. Science $1949 ; 109: 85-7$.

9. Sabin AB. Oral poliovirus vaccine: history of its development and use and current challenge to eliminate poliomyelitis from the world. $J$ Infect Dis $1985 ; 151: 420-36$.

10. Salk JE. Consideration in the preparation and use of poliomyelitis virus vaccine. J Amer Med Ass 1955; 1548 : 1239-48.
11. Dalldorf G, Sickles GM. An Unidentified, Filtrable Agent Isolated From the Feces of Children With Paralysis. Science 1948 ; 16 : 108 : 61-2. 12. Crowell RL, Landau BJ. A short history and introductory background on the coxsackieviruses of group B. Curr Top Microbiol Immunol $1997 ; 223: 1-11$.

13. Pallansch M, Roos R. "Enteroviruses : polioviruses, coxsackieviruses, echoviruses, and newer enteroviruses". In : Knipe DM, Howley PM, editors. Fields Virology. Philadelphia : Lippincott Williams and Wilkins, 2007. pp. 839-93.

14. Archetti I, Dubes GR, Wenner HA. A comparative study of the prototypic Hill strain of ECHO virus, type 9, and several Coxsackie-like viruses related to it antigenically. Arch Gesamte Virusforsch 1959;9:73-91.

15. Dalldorf G, Enders JF, Hammon WM, Sabin AB, Syverton JT, Melnick JL. ENTERIC cytopathogenic human orphan (ECHO) viruses. Science $1955 ; 122: 187-8$

16. Rosen L, Melnick JL, Schmidt J, Wenner HA. Subclassification of enteroviruses and ECHO virus type 34. Brief report. Arch Gesamte Virusforsch $1970 ; 30$ : 89-92.

17. Joki-Korpela P, Hyypia T. Parechoviruses, a novel group of human picornaviruses. Ann Med 2001 ; 33: 466-71.

18. Leveque N, Huguet $\mathrm{P}$, Norder H, Chomel JJ. Les Enterovirus responsables de conjonctivite aiguë hémorragique. Med Mal Infect $2010 ; 40: 212-8$.

19. Tyrrell DA, Parsons R. Some virus isolations from common colds. III. Cytopathic effects in tissue cultures. Lancet $1960 ; 1: 239-42$.

20. Cordey S, Schibler M, Tapparel C, Kaiser L. Rhinovirus : diversité clinique et génomique. Virologie 2008; $12: 361-73$.

21. Tyrrell DA, Chanock RM. Rhinoviruses: a description. Science $1963 ; 141: 152-3$.

22. Ketler A, Hamparian VV, Hilleman MR. Characterization and classification of ECHO 28-rhinovirus-coryzavirus agents. Proc Soc Exp Biol Med 1962; 110:821-31.

23. Zapikian AZ, Conant RM, Hamparian VV, Chanock RM, Chapple PJ, Dick EC, et al. Rhinoviruses: a numbering system. Nature 1967; 213 : 7612.

24. Fenner F. The classification and nomenclature of viruses. Summary of results of meetings of the International Committee on Taxonomy of Viruses in Madrid, September 1975. J Gen Virol 1976; 31 : 463-70.

25. Kalter SS. Enteric viruses of nonhuman primates. Vet Pathol Suppl $1982 ; 7: 33-43$.

26. Lim KA, Benyesh-Melnick M. Typing of viruses by combinations of antiserum pools. Application to typing of enteroviruses (Coxsackie and ECHO). J Immunol $1960 ; 84$ : 309-17.

27. Kenny GE, Cooney MK, Thompson DJ. Analysis of serum pooling schemes for identification of large numbers of viruses. Am J Epidemiol $1970 ; 91: 439-45$.

28. Melnick JL, Wimberly IL. Lyophilized combination pools of enterovirus equine antisera: new LBM pools prepared from reserves of antisera stored frozen for two decades. Bull World Health Organ $1985 ; 63$ : 543-50.

29. Melnick JL, Rennick V, Hampil B, Schmidt NJ, Ho HH. Lyophilized combination pools of enterovirus equine antisera: preparation and test procedures for the identification of field strains of 42 enteroviruses. Bull World Health Organ $1973 ; 48: 263-8$.

30. Melnick JL, Schmidt NJ, Hampil B, Ho HH. Lyophilized combination pools of enterovirus equine antisera: preparation and test procedures for the identification of field strains of 19 group A coxsackievirus serotypes. Intervirology $1977 ; 8: 172-81$.

31. van Loon AM, Cleator GC, Ras A. External quality assessment of enterovirus detection and typing. European Union Concerted Action on Virus Meningitis and Encephalitis. Bull World Health Organ 1999; 77 : 217-23. 32. Oberste MS, Maher K, Kilpatrick DR, Pallansch MA. Molecular evolution of the human enteroviruses: correlation of serotype with VP1 sequence and application to picornavirus classification. J Virol 1999; 73 : 1941-8. 
33. Oberste MS, Maher K, Kilpatrick DR, Flemister MR, Brown BA, Pallansch MA. Typing of human enteroviruses by partial sequencing of VP1. J Clin Microbiol 1999; 37 : 1288-93.

34. Oberste MS, Maher K, Flemister MR, Marchetti G, Kilpatrick DR, Pallansch MA. Comparison of classic and molecular approaches for the identification of untypeable enteroviruses. J Clin Microbiol $2000 ; 38: 1170-4$.

35. Bessaud M, Jegouic S, Joffret ML, Barge C, Balanant J, GouandjikaVasilache I, et al. Characterization of the genome of human enteroviruses: design of generic primers for amplification and sequencing of different regions of the viral genome. J Virol Methods 2008; $149: 277-84$.

36. Caro V, Guillot S, Delpeyroux F, Crainic R. Molecular strategy for 'serotyping' of human enteroviruses. J Gen Virol 2001; 82 : 79-91.

37. Nasri D, Bouslama L, Omar S, Saoudin H, Bourlet T, Aouni M, et al. Typing of human enterovirus by partial sequencing of VP2. J Clin Microbiol $2007 ; 45: 2370-9$.

38. Nix WA, Oberste MS, Pallansch MA. Sensitive, seminested PCR amplification of VP1 sequences for direct identification of all enterovirus serotypes from original clinical specimens. J Clin Microbiol $2006 ; 44: 2698-704$

39. McIntyre CL, Knowles NJ, Simmonds P. Proposals for the classification of human rhinovirus species A, B and C into genotypically assigned types. J Gen Virol 2013; 94 : 1791-806.

40. Kolekar PS, Waman VP, Kale MM, Kulkarni-Kale U. RV-Typer: A Web Server for Typing of Rhinoviruses Using Alignment-Free Approach. PLoS One 2016; 11 : $\mathrm{e} 0149350$.

41. Kroneman A, Vennema H, Deforche K, v d Avoort H, Penaranda S, Oberste MS, et al. An automated genotyping tool for enteroviruses and noroviruses. J Clin Virol 2011; $51: 121-5$.

42. Brown BA, Maher K, Flemister MR, Naraghi-Arani P, Uddin M, Oberste MS, et al. Resolving ambiguities in genetic typing of human enterovirus species $\mathrm{C}$ clinical isolates and identification of enterovirus 96, 99 and 102. J Gen Virol 2009; $90: 1713-23$.

43. Carstens EB, Ball LA. Ratification vote on taxonomic proposals to the International Committee on Taxonomy of Viruses (2008). Arch Virol $2009 ; 154: 1181-8$.

44. Lomakina NF, Shustova EY, Strizhakova OM, Drexler JF, Lukashev AN. Epizootic of vesicular disease in pigs caused by coxsackievirus B4 in the Soviet Union in 1975. J Gen Virol 2016; 97 :49-52.

45. Adams MJ, King AM, Carstens EB. Ratification vote on taxonomic proposals to the International Committee on Taxonomy of Viruses (2013). Arch Virol 2013; 158 : 2023-30.

46. Zhang Y, Hong M, Sun Q, Zhu S, Tsewang S, Li X, et al. Molecular typing and characterization of a new serotype of human enterovirus (EVB111) identified in China. Virus Res 2014; $183: 75-80$.

47. Harvala H, Sharp CP, Ngole EM, Delaporte E, Peeters M, Simmonds P. Detection and genetic characterization of enteroviruses circulating among wild populations of chimpanzees in Cameroon: relationship with human and simian enteroviruses. $J$ Virol $2011 ; 85$ : 4480-6.

48. Mombo IM, Lukashev AN, Bleicker T, Brunink S, Berthet N, Maganga GD, et al. African Non-Human Primates Host Diverse Enteroviruses. PLoS One 2017; 12 : $\mathrm{e} 0169067$.

49. Oberste MS, Feeroz MM, Maher K, Nix WA, Engel GA, Begum S, et al. Naturally acquired picornavirus infections in primates at the Dhaka zoo. J Virol 2013; $87: 572-80$.

50. Tokarz R, Haq S, Sameroff S, Howie SR, Lipkin WI. Genomic analysis of coxsackieviruses A1, A19, A22, enteroviruses 113 and 104 : viruses representing two clades with distinct tropism within enterovirus C. J Gen Virol 2013 ; 94 : 1995-2004.

51. Razafindratsimandresy R, Joffret ML, Delpeyroux F, Heraud JM. First full genome sequence of a human enterovirus A120, isolated in Madagascar. Genome Announc 2014; 2 : e00566-614.
52. Harvala H, Van Nguyen D, McIntyre C, Ahuka-Mundeke S, Ngole EM, Delaporte E, et al. Co-circulation of enteroviruses between apes and humans. J Gen Virol 2014; 95 : 403-7.

53. Deshpande JM, Sharma DK, Saxena VK, Shetty SA, Qureshi TH, Nalavade UP. Genomic characterization of two new enterovirus types, EV-A114 and EV-A121. J Med Microbiol 2016; 65: 1465-71.

54. Sadeuh-Mba SA, Bessaud M, Joffret ML, Endegue Zanga MC, Balanant J, Mpoudi Ngole E, et al. Characterization of Enteroviruses from non-human primates in cameroon revealed virus types widespread in humans along with candidate new types and species. PLoS Negl Trop Dis 2014 ; 8 : e3052.

55. McErlean P, Shackelton LA, Andrews E, Webster DR, Lambert SB, Nissen MD, et al. Distinguishing molecular features and clinical characteristics of a putative new rhinovirus species, human rhinovirus C (HRVC). PLoS One 2008; 3 : e1847.

56. Simmonds P, McIntyre C, Savolainen-Kopra C, Tapparel C, Mackay IM, Hovi T. Proposals for the classification of human rhinovirus species C into genotypically assigned types. J Gen Virol $2010 ; 91: 2409-19$.

57. Oberste MS, Maher K, Schnurr D, Flemister MR, Lovchik JC, Peters $\mathrm{H}$, et al. Enterovirus 68 is associated with respiratory illness and shares biological features with both the enteroviruses and the rhinoviruses. J Gen Virol 2004 ; 85 : 2577-84.

58. Blomqvist $S$, Savolainen C, Raman L, Roivainen M, Hovi T. Human rhinovirus 87 and enterovirus 68 represent a unique serotype with rhinovirus and enterovirus features. J Clin Microbiol 2002; 40 : 4218-23.

59. Yozwiak NL, Skewes-Cox P, Gordon A, Saborio S, Kuan G, Balmaseda A, et al. Human enterovirus 109 : a novel interspecies recombinant enterovirus isolated from a case of acute pediatric respiratory illness in Nicaragua. J Virol 2010; 84 : 9047-58.

60. Daleno C, Piralla A, Scala A, Baldanti F, Usonis V, Principi N, et al. Complete genome sequence of a novel human enterovirus C (HEVC117) identified in a child with community-acquired pneumonia. $J$ Virol 2012;86:10888-9.

61. Daleno C, Greenberg D, Piralla A, Scala A, Baldanti F, Principi N, et al. A novel human enterovirus C (EV-C118) identified in two children hospitalised because of acute otitis media and community-acquired pneumonia in Israel. J Clin Virol 2013; 56 : 159-62.

62. Woo PC, Lau SK, Li T, Jose S, Yip CC, Huang Y, et al. A novel dromedary camel enterovirus in the family Picornaviridae from dromedaries in the Middle East. J Gen Virol 2015 ; 96 : 1723-31.

63. Lukashev AN, Vakulenko YA. Molecular evolution of types in nonpolio enteroviruses. J Gen Virol 2017 ; 98 : 2968-81.

64. Bessaud M, Razafindratsimandresy R, Nougairede A, Joffret ML, Deshpande JM, Dubot-Peres A, et al. Molecular comparison and evolutionary analyses of VP1 nucleotide sequences of new African human enterovirus 71 isolates reveal a wide genetic diversity. PLoS One 2014; 9 : e 90624.

65. Saxena VK, Sane S, Nadkarni SS, Sharma DK, Deshpande JM. Genetic diversity of enterovirus A71. India. Emerg Infect Dis 2015 ; 21 : 123-6.

66. Simmonds P. Methods for virus classification and the challenge of incorporating metagenomic sequence data. J Gen Virol 2015 ; 96 : 1193206.

67. Bouslama L, Nasri D, Chollet L, Belguith K, Bourlet T, Aouni M, et al. Natural recombination event within the capsid genomic region leading to a chimeric strain of human enterovirus B. J Virol 2007 ; 81 : 8944-52.

68. Mueller JE, Bessaud M, Huang QS, Martinez LC, Barril PA, Morel V, et al. Environmental poliovirus surveillance during oral poliovirus vaccine and inactivated poliovirus vaccine use in Cordoba Province, Argentina. Appl Environ Microbiol 2009; 75 : 1395-401.

69. Bessaud M, Joffret ML, Blondel B, Delpeyroux F. Exchanges of genomic domains between poliovirus and other cocirculating species $\mathrm{C}$ enteroviruses reveal a high degree of plasticity. Sci Rep 2016; 6:38831. 